\title{
DNA methyltransferase 3b silencing affects locus-specific DNA methylation and inhibits proliferation, migration and invasion in human hepatocellular carcinoma SMMC-7721 and BEL-7402 cells
}

\author{
JIA-CHEN WANG, ZHAO WANG, YU-XIA FAN, YA-QING SI and JIA-XIANG WANG
}

Department of Medicine, The First Affiliated Hospital of Zhengzhou University, Zhengzhou, Henan 450052, P.R. China

Received June 12, 2014; Accepted March 6, 2015

DOI: $10.3892 / 01.2015 .3077$

\begin{abstract}
DNA methylation is an important regulator of gene transcription, and its role in carcinogenesis has been a topic of considerable interest in previous years. The present study examined the influence of DNA methyltransferase 3b (DNMT3b) on cell proliferation, migration and invasion, and the methylation status of identified tumor suppressor genes in hepatoma SMMC-7721 and BEL-7402 cells. DNMT3b was silenced by small interfering RNA (siRNA) in human hepatocellular carcinoma cell lines. Transfection efficiency was verified using a fluorescent imaging system, reverse transcription polymerase chain reaction (RT-PCR) and western blotting. A cell proliferation assay was performed to evaluate cell viability. Cell cycle distribution and apoptosis were analyzed by flow cytometry. The migratory and invasive ability of cells was measured using a Transwell assay. Methylation-specific PCR (MSP) was performed to assess methylation in the promoter region of genes. The present data revealed that DNMT3b siRNA successfully inhibited expression of the DNMT3b gene in these two liver cancer cell lines and therefore inhibited the proliferation of the transfected cells, stimulated apoptosis in the cells, led to an accumulation of cells in the $G_{2} / M$ phase and decreased cell migration and invasion. It was also found that silencing DNMT3b expression results in hypomethylation of specific sets of gene promoters and increases the expression of distinct set of genes in HCC cell lines. The present study is therefore useful for assessing the specificity of emerging action based on the altered expression of associated regulatory genes, particularly in methylation-silenced genes.
\end{abstract}

\section{Introduction}

Hepatocellular carcinoma (HCC) is the sixth most common type of cancer, the third leading cause of cancer-associated

Correspondence to: Dr Jia-Chen Wang, Department of Medicine, The First Affiliated Hospital of Zhengzhou University, 1 Jian-she Dong Road, Zhengzhou, Henan 450052, P.R. China

E-mail: cloudbio-tech@hotmail.com

Key words: DNA mteyltransferase 3b, epigenetic, methylation, small interfering RNA, hepatocellular carcinoma cells mortality worldwide and the second leading cause of cancer-associated mortality in China $(1,2)$. HCC is caused by a complex interaction between numerous factors (3). Aberrant hypermethylation of $\mathrm{CpG}$ islands has recently been implicated in hepatocarcinogenesis, and it has been reported that tumor suppressor genes in HCC are affected by silencing through hypermethylation (4). It is well known that DNA methylation is involved in the early developmental stages of HCC in patients with a history of chronic liver disease. It has recently been suggested that aberrant DNA methylation of $\mathrm{CpG}$ islands in HCC is an early and frequent event, and that the stepwise progression of methylation events contributes to multistep hepatocarcinogenesis (5-7).

DNA methylation is one of several epigenetic mechanisms that cells use to control genes and it plays an important role in regulating cell growth and differentiation, signal transduction, DNA repair, tumor metastasis and angiogenesis $(8,9)$. The mammalian genome encodes two cytosine methyltransferases of the DNMT3 family, DNMT3a and DNMT3b. The two enzymes are of considerable significance in de novo DNA transmethylation and maintenance of methylation $(10,11)$. DNA methyltransferase 3b (DNMT3b) is the enzyme that is primarily responsible for methylation of certain genomic regions, including pericentromeric repetitive sequences and CpG islands on the inactive C chromosome. If the DNMT3a and DNMT3b enzymes are defective or absent, cancer cells not only lose methylation at satellite sequences but acquire methylation in normally unmethylated promoter regions (12).

The level of DNMT1, DNMT3a and DNMT3b mRNA in $\mathrm{HCC}$ is significantly increased compared with non-cancerous liver tissues (13). The methylated sequences are not recognized by transcription factors, which prevents the expression of corresponding genes. Tumor suppressor genes are silenced by hypermethylation in numerous cancer types $(14,15)$. Gene silencing by epigenetic mechanisms, including DNA methylation, has been reported to contribute to HCC development (16-18). These epigenetic mechanisms, alone or in combination with genetic modifications such as mutations, may lead to the inactivation of tumor suppressor genes, including RASSF1a and APC, and therefore promote hepatocarcinogenesis (19-23).

In the present study, the role of DNMT3b in the regulation of the cell cycle, initiation of apoptosis, and migratory and invasive ability of liver cancer cells was investigated and the effect of the methylation status of $\mathrm{CpG}$ promoter islands of 
known tumor suppressor genes was also investigated in the HCC cells.

\section{Materials and methods}

Antibodies and reagents. An expression vector for small interfering RNA (siRNA) against DNMT3b, a control siRNA expression vector, transfection reagents, a transfection intermediary agent, DNMT3b rabbit polyclonal antibody (catalog no. sc-20704) and fluorescein isothiocyanate (FITC) labeled goat anti rabbit immunoglobulin (Ig)G (catalog no. sc-2012) were all obtained from Santa Cruz Biotechnology, Inc. Dallas, TX, USA. RPMI-1640 and fetal bovine serum (FBS) were obtained from HyClone (Logan, UT, USA). Reagents for western blotting and an MTT assay were obtained from Sigma-Aldrich (St. Louis, MO, USA) or Applygen Technologies, Inc. (Beijing, China). A genomic DNA Mini kit was obtained from (Axygen Biosciences, Union City, CA, USA). Bisulfite was obtained from (Sigma-Aldrich).

Cell culture. The human HCC SMMC-7721 and BEL-7402 cell lines were obtained from the American Type Culture Collection (Manassas, VA, USA) and grown in RPMI-1640 supplemented with $10 \%$ FBS, 100 units $/ \mathrm{ml}$ penicillin and 100 units $/ \mathrm{ml}$ streptomycin at $37^{\circ} \mathrm{C}$ in a humidified incubator with a $5 \%$ $\mathrm{CO}_{2}$ atmosphere. The cells were used in experiments when they reached $>80 \%$ confluency.

siRNA transfection. In total, $50 \mathrm{nmol} / 1 \mathrm{DNMT} 3 \mathrm{~b}$ siRNA (Santa Cruz Biotechnology, Inc.) or $50 \mathrm{nmol} / \mathrm{l}$ control siRNA was transfected into cells by lipofectin (Invitrogen, Carlsbad, CA, USA), according to the manufacturer's instructions. Briefly, the cells were seeded in six-well plates and incubated overnight, and then transfected with $50 \mathrm{nmol} / 1$ siRNA for $6 \mathrm{~h}$ using $6 \mu \mathrm{l}$ lipofectin per well. The cells were cultured for an additional $48 \mathrm{~h}$ prior to the experiment being performed. Images of the fluorescence of fluorescein-labeled control siRNA in SMMC7721 cells were captured using a Nikon microscopic fluorescent imaging system (Nikon, Tokyo, Japan) to determine the transfection efficiency. The parameters of the fluorescent filter were: Excitation filter 435/10 (catalog no., MBE 34232); dichtoic mirror DM455 (catalog no., MBE 34270); and barrier filter NBA480 (catalog no., MBE 34535).

MTT cell proliferation assay. Cell proliferation was evaluated using an MTT cell viability assay, as previously described (22). The cells for the cell proliferation assay were in the log phase of growth throughout the assay. In total, $3 \times 10^{3}$ cells $/ \mathrm{ml}$ were cultured in a 96-well plate. MTT was added at 24 and $36 \mathrm{~h}$ after siRNA transfection. The cells were incubated for $4 \mathrm{~h}$ in the presence of the MTT reagent, and the cells were then lysed with dimethyl sulfoxide (DMSO). The optical density (OD) was measured by determining the absorbance at $490 \mathrm{~nm}$. The assay was repeated at least three times. The ratio of the mean OD at $490 \mathrm{~nm}$ in the transfection groups compared with the OD at $490 \mathrm{~nm}$ in the control group was used to demonstrate the cell survival rate.

Total protein and genomic DNA extraction. Total protein and genomic DNA were extracted $36 \mathrm{~h}$ after transfection. In general, the cells were detached and collected using trypsin, washed three times using PBS and then mixed with fresh lysis solution consisting of $50 \mathrm{mmol} / 1$ Tris, $0.3 \mathrm{~mol} / 1 \mathrm{NaCl}$, $0.5 \%$ Triton X-100, $30 \mu \mathrm{g} / \mathrm{ml}$ leupeptin and $5 \mu \mathrm{g} / \mathrm{ml}$ aprotinin. The mixture was then centrifuged at $20,000 \mathrm{x}$ g for $20 \mathrm{~min}$ at $4^{\circ} \mathrm{C}$. The supernatant contained the total cell protein, and the protein concentration was determined using the Bradford method. Extraction of genomic DNA was performed using the Genomic DNA Mini kit (Qiagen, Shanghai, China), according to the manufacturer's instructions. The concentration was quantitatively analyzed by measuring the $\mathrm{OD}_{260}$ using the NanoDrop 1000 (Thermo Fisher Scientific, Wilmington, DE, USA) and the purity was quantitatively analyzed using the ratio of $\mathrm{OD}_{260}$ to $\mathrm{OD}_{280}$.

Reverse transcription-quantitative polymerase chain reaction (RT-qPCR). Total mRNA was extracted by RNAiso Plus (Takara Bio, Inc., Otsu, Japan) and $2 \mu \mathrm{g}$ of mRNA was reverse transcribed using Moloney murine leukemia virus reverse transcriptase, ribonuclease $\mathrm{H}$ minus (Takara Bio, Inc.). PCR was performed using cDNA, specific primers and PCR master mix (Takara Bio, Inc.). The cDNA products were separated by electrophoresis on $1.5 \%(\mathrm{w} / \mathrm{v})$ agarose gels and visualized under ultraviolet light subsequent to ethidium bromide staining. RT-qPCR was performed on a Real-Time PCR Optical System (Bio-Rad Laboratories, Hercules, CA, USA), SDS software version 2.1 (Bio-Rad Laboratories), following a cycling protocol that consisted of $95^{\circ} \mathrm{C}$ for $30 \mathrm{sec}$, followed by 40 cycles of $95^{\circ} \mathrm{C}$ for $10 \mathrm{sec}$, and $58^{\circ} \mathrm{C}$ for $5 \mathrm{sec}$. Fluorescence readings were taken during the $58^{\circ} \mathrm{C}$ step. Quantitative real-time PCR was performed at least three times, and a no-template control was included as a negative control. RT-qPCR was measured using SYBR green (Takara Bio, Inc.) with the following primers: DNMT3b forward, 5'-CCTGCTGAATTACTCACGCCCC-3' and reverse, 5'-GTCTGTGTAGTGCACAGGAAAGCC-3'.

Cell cycle and apoptosis flow cytometry. Cell apoptosis and cell cycle distribution were finally evaluated using the Annexin V-FITC/propidium iodide apoptosis detection kit (Qiagen) and cell cycle kit (Qiagen), according to the manufacturer's instructions. Flow cytometry analyses were also performed on Epics XL (Beckman Coulter, Brea, CA, USA) and processed using the corresponding software.

Cell invasion and migration assay. Cells in the siRNA-transfected group, and siRNA-mock transfected group were detached from culture plates in the absence of trypsin (HyClone, Logan, UT, USA). The cells were resuspended at a density of $2 \times 10^{5}$ cells/ml in DMEM and $200 \mu 1$ of the cell suspension was added to the upper chamber of an $8-\mu \mathrm{m}$ pore Transwell insert (Corning Life Sciences, Logan, UT, USA) in triplicate. DMEM culture solution $(600 \mu \mathrm{l})$ containing $10 \%$ FBS was added to the lower chamber of each well and incubated for $24 \mathrm{~h}$ at $37^{\circ} \mathrm{C}$. The non-migratory cells on the upper surface of the membrane were removed and the migratory cells were stained in $0.1 \%$ crystal violet. To count the migrated cells in five random high-power fields, invasion assays were performed in a similar manner to the migration assays. Transwell inserts with $8-\mu \mathrm{m}$ pores (Corning Life Sciences) were coated with $100 \mu 1$ Matrigel (Becton-Dickinson, Franklin Lakes, NJ, 
Table I. DNA sequences of all primers used in methylation sensitive polymerase chain reaction.

\begin{tabular}{|c|c|c|c|}
\hline Gene & Direction & Methylated primer & Unmethylated primer \\
\hline \multirow[t]{2}{*}{$A P C$} & $\mathrm{~F}$ & 5'-TATTGCGGAGTGCGGGTC-3' & 5'-GTGTTTTATTGTGGAGTGTGGGTT-3' \\
\hline & $\mathrm{R}$ & 5'-TCGACGAACTCCCGACGA-3' & 5'-CСАATCAACAAACTCCCAACAA-3' \\
\hline \multirow[t]{2}{*}{$C A S P 8$} & $\mathrm{~F}$ & 5'-TAGGGGATTCGGACATTGCGA-3' & 5'-TAGGGGATTTGGAGATTGTGTA-3' \\
\hline & $\mathrm{R}$ & 5'-CGTATATCTACATTCGAAACG-3' & 5'-CCATATATATCTACATTCAAAACAA-3' \\
\hline \multirow[t]{2}{*}{$C C N D 1$} & $\mathrm{~F}$ & 5'-TACGTGTTAGGGTCGATCG-3' & 5'-GTTATGTTATGTTTGTTGTATG-3' \\
\hline & $\mathrm{R}$ & 5'-CGAAATATCTACGCTAAACG-3' & 5'-TAAAATCCACCAACACAATCA-3' \\
\hline \multirow[t]{2}{*}{ FHIT } & $\mathrm{F}$ & 5'-TTGGGGCGCGGGTTTGGGTTTTTACGC-3' & 5'-TTGGGGTGTGGGTTTGGGTTTTTATG-3' \\
\hline & $\mathrm{R}$ & 5'-CGTAAACGAGCGCGACCCCACTA-3' & 5'-CATAAACACCAACCCCACTA-3' \\
\hline \multirow[t]{2}{*}{ MTSS1 } & $\mathrm{F}$ & 5'-GAGAGCGCGTTTTCGTTTGGC-3' & 5'-GAGAGTGTGTTTTTGTTTGGT-3' \\
\hline & $\mathrm{R}$ & 5'-CGCCTCCTTTTCACTCCTACG-3' & 5'-CСАССТССТТTTCACТССТАСА-3' \\
\hline \multirow[t]{2}{*}{ pl6 } & $\mathrm{F}$ & 5'-TTATTAGAGGGTGGGGCGGATCGC-3' & 5'-TTATTAGAGGGTGGGGTGGATTGT-3' \\
\hline & $\mathrm{R}$ & 5'-ACCCCGAACCGCGACCGTAA-3' & 5'-CAACCCCAAACCACAACCATAA-3' \\
\hline \multirow[t]{2}{*}{ RASSF Ia } & $\mathrm{F}$ & 5'-GTGTTAACGCGTTGCGTATC-3' & 5'-TTTGGTTGAGTGTGTTAATGTG-3' \\
\hline & $\mathrm{R}$ & 5'-AACCCCGCGAACTAAAAACGA-3' & 5'-CAAACCCCACAAACTAAAAACAA-3' \\
\hline \multirow[t]{2}{*}{$R B 1$} & $\mathrm{~F}$ & 5'-GGGAGTTTCGCGGACGTGAC-3' & 5'-GGGAGTTTTGTGGATGTGAT-3' \\
\hline & $\mathrm{R}$ & 5'-ACGTCGAAACACGCCCCG-3' & 5'-ACATCAAAACAACCCCA-3' \\
\hline
\end{tabular}

F, forward; R, reverse.

USA) that was diluted 1:4 in ice-cold DMEM and left to gel at $37^{\circ} \mathrm{C}$. The cells were resuspended in DMEM and $200 \mu \mathrm{l}$ of the $5 \times 10^{5}$ cells $/ \mathrm{ml}$ cell suspension was seeded in the upper chamber. The culture plates were incubated for $48 \mathrm{~h}$ at $37^{\circ} \mathrm{C}$, and the cells were stained and counted, as aforementioned.

Western blotting. The expression of DNMT3b and other genes in the cell lines were measured using western blotting. The protein sample was diluted using $5 \mathrm{X}$ sample buffer at the ratio of 4:1. Prior to performing SDS-PAGE, the analytical sample was denatured at $100^{\circ} \mathrm{C}$ for $5 \mathrm{~min}$. Subsequent to SDS-PAGE, the proteins in the gel were transferred to polyvinylidene fluoride membranes that were incubated in $5 \%$ fat-free milk at room temperature to block non-specific proteins. The membranes were then incubated in antibodies against DNMT3b or cyclin D1 rabbit polyclonal antibody (catalog no. sc-753; Santa Cruz Biotechnology, Inc.), and diluted at a ratio of $1: 200$ at $4^{\circ} \mathrm{C}$ overnight. Subsequent to washing with Tris buffered saline with Tween 20 (TBST), consisting of $50 \mathrm{mM}$ Tris base, $0.9 \%$ $\mathrm{NaCl}$ and $0.05 \%$ Tween 20 (pH 7.5), the membranes were incubated in FITC-labeled goat anti-mouse IgG for all test genes solution at $37^{\circ} \mathrm{C}$ for $1 \mathrm{~h}$, and diluted at the ratio of $1: 8,000$. Subsequent to washing with TBST, the membranes were processed using enhanced chemiluminescence and exposed to $\mathrm{X}$-rays for $5 \mathrm{~min}$. $\beta$-actin was used as the internal reference.

Methylation-specific PCR (MSP). Genomic DNA from mock control and DNMT3b-silenced cells was isolated and the 5-methylcytosine residues were chemically converted to uracil by bisulfite treatment. This DNA was subsequently used as a template in PCR reactions with methylation-sensitive and insensitive primer pairs. To ascertain that the employed primer sets reliably distinguished methylated annealing sites from unmethylated sites, genomic DNA was isolated from white blood cells and one-half of the genomic DNA was methylated to saturation with methyltransferase from Spiroplasma sp. strain MQ1, while the other half was used without any processing. In total, $2 \mathrm{mg}$ of genomic DNA was modified by sodium bisulfite treatment at $50^{\circ} \mathrm{C}$ for $16 \mathrm{~h}$. Subsequent to the removal of bisulfite and completion of the chemical conversion, this modified DNA was used as a template for PCR. PCR was performed twice for each DNA sample. MSP primers were designed and synthesized by Beijing AuGCT DNASYN Biotechnology, Co., Ltd. (Beijing, China). The sequence of the methylated primer for each gene is listed in Table I.

For the reaction using the methylated primer, DNA was denatured at $95^{\circ} \mathrm{C}$ for $30 \mathrm{sec}$ and the PCR products were amplified in the thermal cycle, as follows: $30 \mathrm{sec}$ at $94^{\circ} \mathrm{C}, 40 \mathrm{sec}$ at $58^{\circ} \mathrm{C}$ and $30 \mathrm{sec}$ at $72^{\circ} \mathrm{C}$ for 35 cycles; and the final elongation was performed at $72^{\circ} \mathrm{C}$ for $4 \mathrm{~min}$. For the reaction using the unmethylated primer, the process was similar, with the exception of the cycles being performed for $30 \mathrm{sec}$ at $94^{\circ} \mathrm{C}, 40 \mathrm{sec}$ at $55^{\circ} \mathrm{C}$ and $30 \mathrm{sec}$ at $72^{\circ} \mathrm{C}$ for a total of 35 cycles. The product of MSP was maintained at $4^{\circ} \mathrm{C}$ and analyzed by gel electrophoresis.

Statistical analysis. All data are expressed as the mean \pm standard deviation. Repeated measures analysis of variance was used to compare the differences between the groups and various times using SPSS software, version 13.0 (Chicago, IL, USA). $\mathrm{P}<0.05$ was considered to indicate a statistically significant difference.

\section{Results}

siRNA transfection downregulates the expression of DNMT3b and inhibits the proliferation of SMMC7721 and 

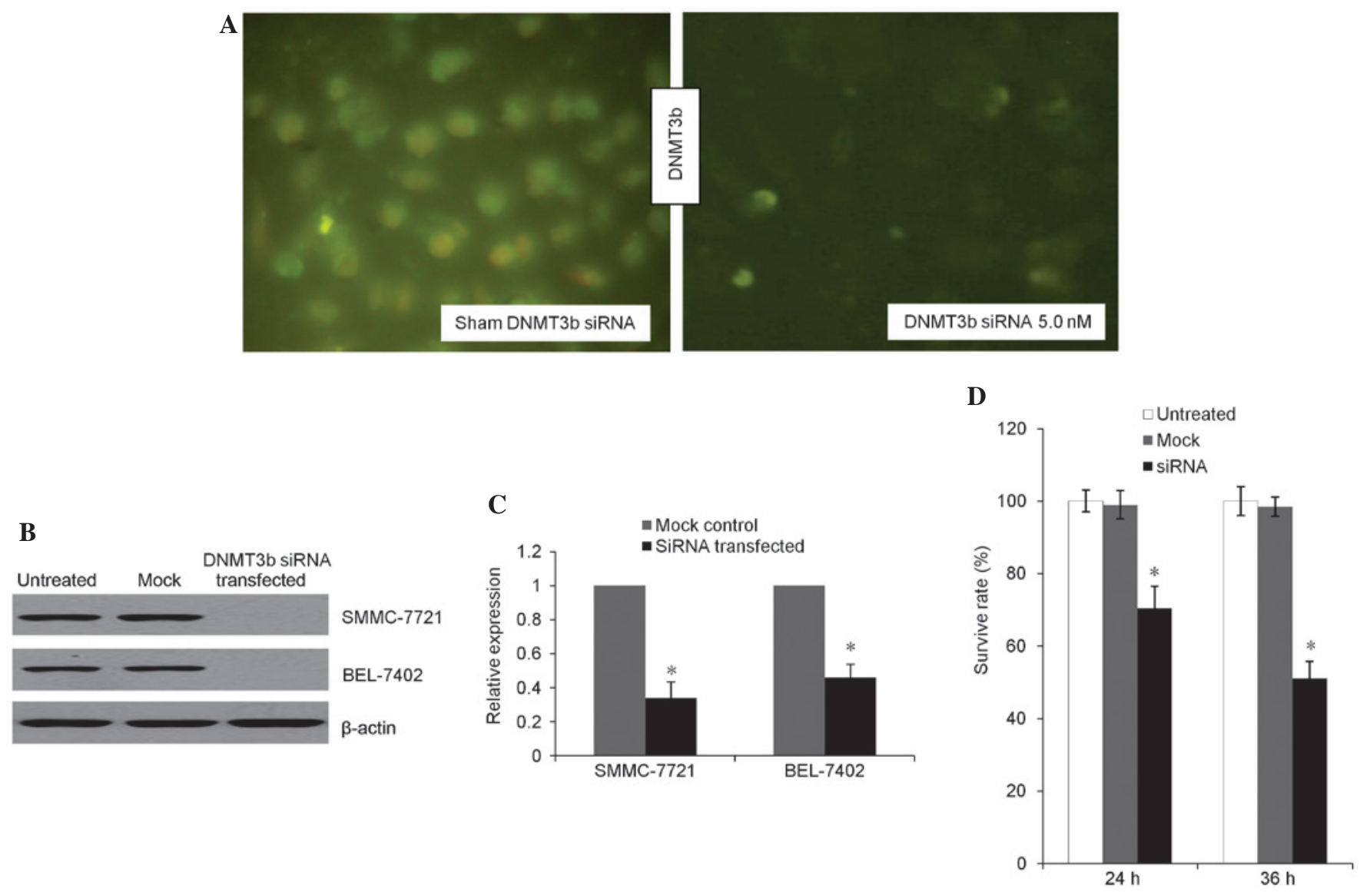

Figure 1. DNMT3b silencing efficency and evaluation of the cell proliferation. (A) Image of SMMC-7721 cells transfected with the fluorescein-labeled control siRNA expression vector (magnification, $x 100$ ). The transfection efficiency $>90 \%$. (B) Western blotting to determine the expression of DNMT3b in SMMC-7721 and BEL-7402 cells, with $\beta$-actin as the internal reference. (C) DNMT3b expression dramtically decreased in the transfected group compared with the mock control. (D) Cell proliferation decreased in transfected group. DNMT3b, DNA methyltransferase; siRNA, small interfering RNA.

BEL-7402 cells. Microscopic fluorescent imaging (Fig. 1A) revealed a decreased DNMT3b signal in the transfection group. The presence of green fluorescence in the SMMC7721 cells was transfected by control siRNA expression vectors and indicated a high efficiency of transfection (>90\%). Western blotting (Fig. 1B) revealed that the expression of DNMT3b was inhibited in the transfection group. The expression of DNMT3b mRNA (Fig. 1C) was revealed to be decreased in the transfection group compared with the mock control. Prior to siRNA transfection, no significant difference in the cell viability was found between the treated and untreated groups. At 24 and $36 \mathrm{~h}$ subsequent to transfection, the survival rate in the transfection group decreased to 71.6 and $53.7 \%$, respectively (Fig. 1D). Therefore, total protein and genomic DNA was extracted $36 \mathrm{~h}$ subsequent to transfection for further analysis.

Downregulation of DNMT3b stimulates cell cycle arrest and enhanced apoptosis. In cell cycle analysis, the percentage of cells in the $G_{2}$ phase in transfection groups was found to be significantly increased $(\mathrm{P}<0.05)$. No difference in the $G_{1}$ and $S$ phase distribution was observed between the groups (Fig. 2A and B). Compared with the negative control, the early apoptosis and late apoptosis rates were increased in groups with decreased DNMT3b expression, across all experimental cell lines (Fig. 2C and D).
Decreased DNMT3b expression inhibits cell migration and invasion ability. Subsequent to the DNMT3b gene being inhibited, the migration capacity of cells declined, with the cell population migrating through the artificial membrane being decreased compared with the non-transfected group $(\mathrm{P}<0.05$; Fig. 3A and $\mathrm{B})$. The invasion of tumor cells through the ECM is an important step in tumor metastasis. Therefore, the number of cells migrating through the Matrigel was counted and it was found that, compared with non-transfected cells, the $D N M T 3 b$-silenced cells demonstrated significantly decreased invasion ( $\mathrm{P}<0.05$; Fig. $3 \mathrm{C}$ and $\mathrm{D})$.

DNMT3b silencing affects the methylation status of genes associated with HCC. Previous studies have reported that silencing of $D N M T 3 b$ does not evidently affect the DNA methylation of any of the genes in cells derived from colon cancer $(24,25)$. To determine whether the same effect of DNMT3b downregulation is observed in $\mathrm{HCC}$ cells, the methylation status of eight tumor suppressor gene promoters was evaluated using MSP. Data from this experiment demonstrated clearly that the genome promoters of the p16 and FHIT genes are hypermethylated and remain hypermethylated even following the decrease in DNMT3b expression (Fig. 4). By contrast, the copies of genes encoding $C C N D 1, R B 1$ and $C A S P 8$ in the genome of control cells were found to be hypomethylated, and as expected, remained that way even subsequent to the 
A
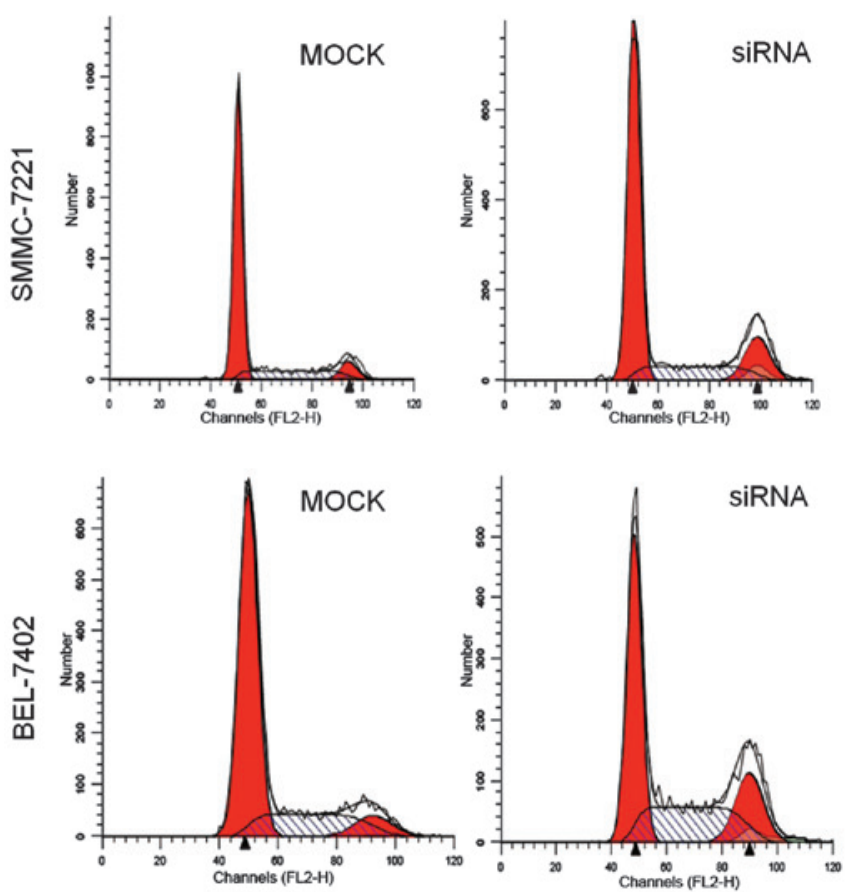

C

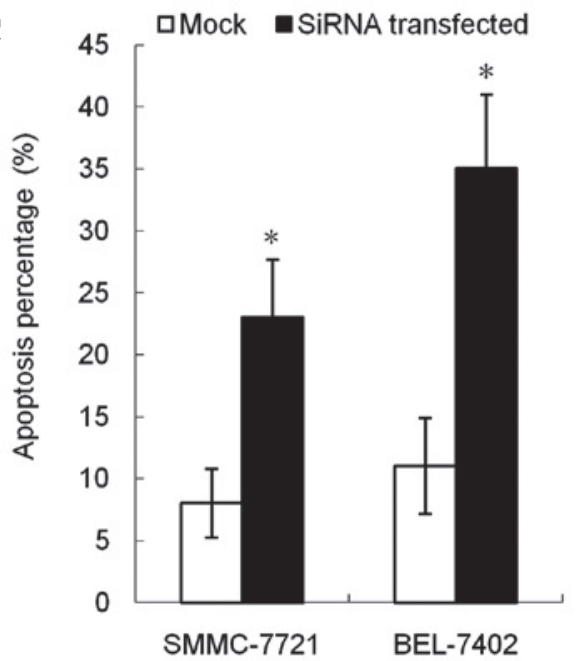

\section{B}

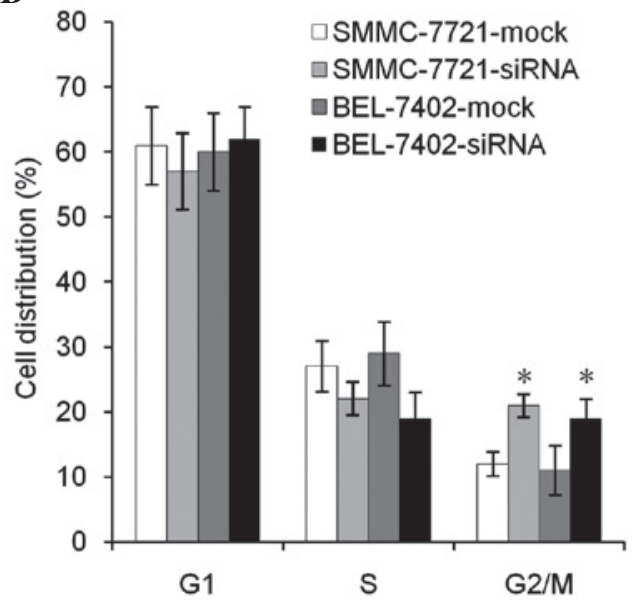

D
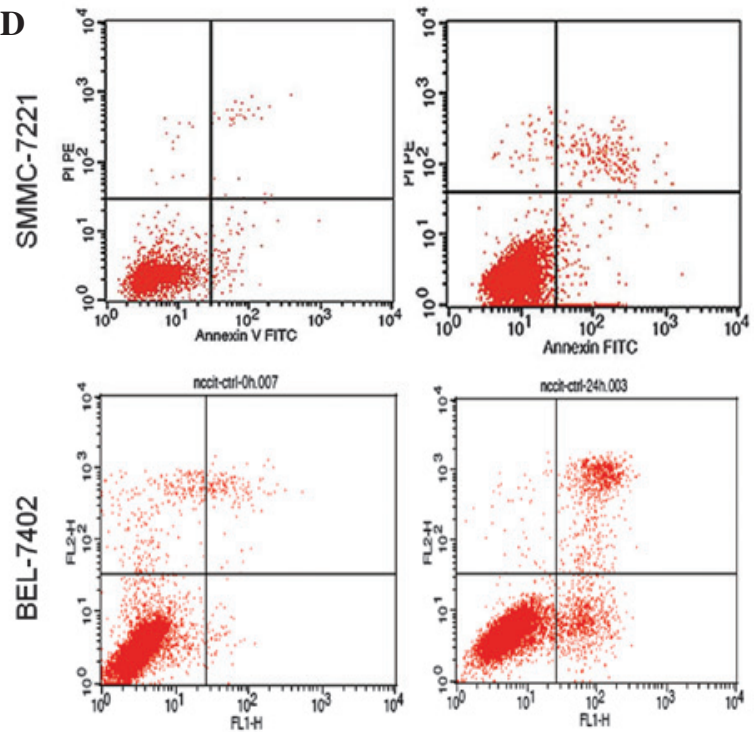

Figure 2. Summary of $\mathrm{G}_{2} / \mathrm{M}$ phase distribution and the percentage of apoptotic cells. The transfected group demonstrated a significant increase in the (A and B) $\mathrm{G}_{2} / \mathrm{M}$ phase cell cycle distribution and $(\mathrm{C}$ and $\mathrm{D})$ percentage of apoptotic cells. * P<0.05 vs. mock control. si RNA, small interfering RNA; FITC, fluorescein isothiocyanate.

reduction in DNMT3b expression (Fig. 4). It was also notable that the gene promoters for MTSS1, RASSFla and APC are differentially methylated on the two alleles. From the nine tumor suppressor genes scrutinized in the present study, it was demonstrated that DNMT3b downregulation resulted in the specific loss of methylation at the promoters of the MTSS1, RASSFla and APC genes (Fig. 4).

\section{Discussion}

The DNA methylation landscape is substantially altered in cancer, resulting in considerable effects on gene transcription and genomic stability (10). Since DNMTs are enzymes that mediate methylation, dissecting the contribution of the enzymes to the process of tumorigenesis represents an important step towards understanding the mechanisms through which aberrant DNA methylation in cancer is generated (26). A previous study found that the expression of DNMT3b increased more in the majority of HCC cell lines, particularly in BEL-7402 and SMMC-7721 cells, compared with the normal and pericarcinoma cell lines used (27). Therefore, the BEL-7402 and SMMC-7721 cell lines were used in the present study. The data revealed that DNMT3b siRNA successfully inhibited the expression of the DNMT3b gene in these two liver cancer cell lines and consequently inhibited the proliferation of transfected cells, stimulated apoptosis and resulted in the accumulation of cells in the $\mathrm{G}_{2} / \mathrm{M}$ phase. Several gene promoter regions were directly regulated by DNMT3b. 

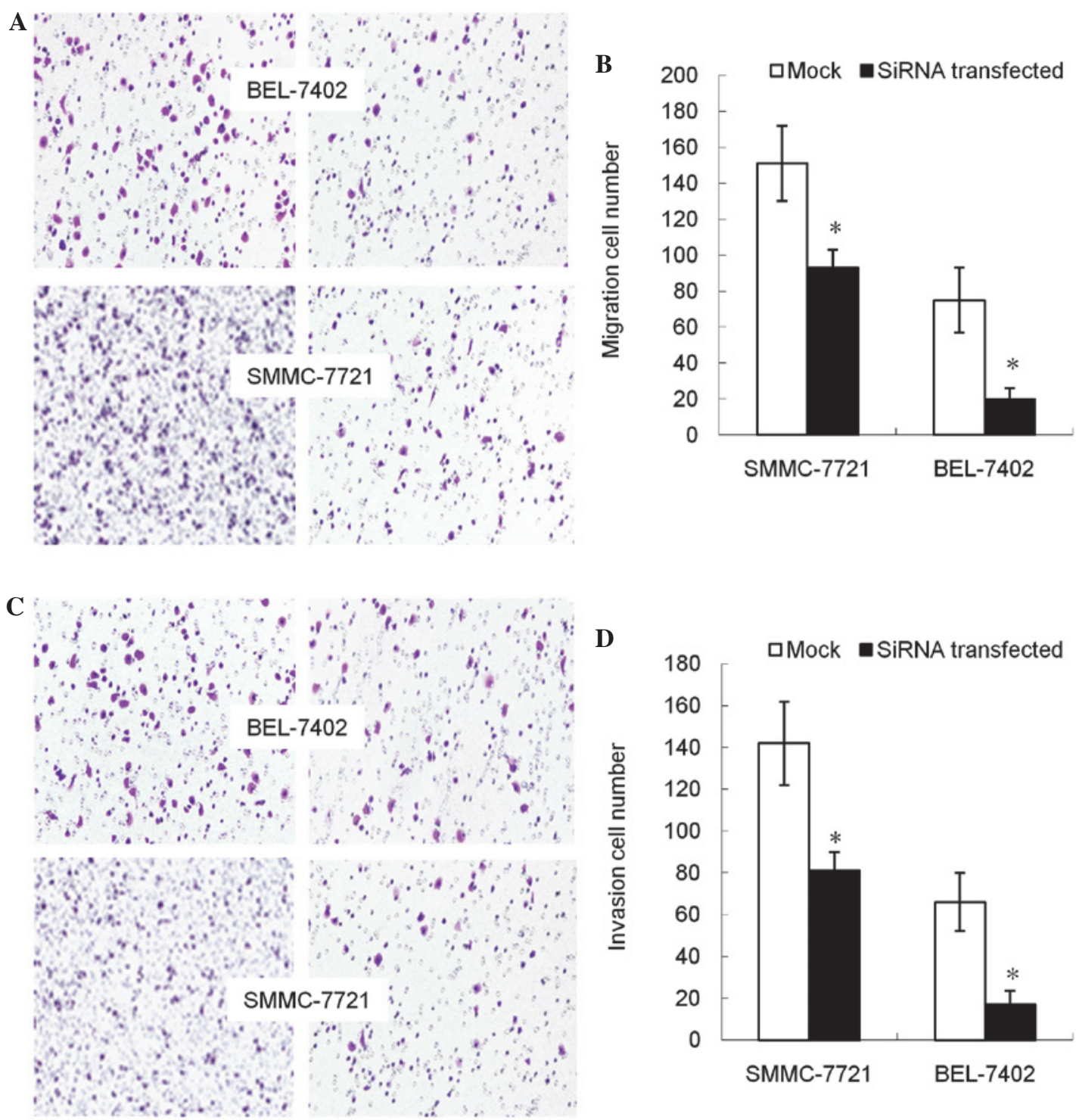

Figure 3. Targeting DNMT3b inhibits tumor migration and invasion in vitro. (A and B) The cells that crossed the polycarbonate membrane of the Transwell chamber were stained with crystal violet to detect the migration of cells (magnification, x100). ${ }^{*} \mathrm{P}<0.01$ vs. mock control. (C and D) The glioma cells that crossed the Matrigel-coated polycarbonate membrane of the Transwell chamber were stained with crystal violet to detect the invasion of cells (magnification, $\mathrm{x} 200)$. ${ }^{*} \mathrm{P}<0.01$. DNMT3b, DNA methyltransferase 3b; SiRNA, small interfering RNA.

The present data also revealed that cell proliferation was dramatically affected by reduced DNMT3b levels. This finding was attributed to enhanced apoptosis, suggesting that DNMT3b targets a set of genes with products that inhibit apoptosis. As expected, the apoptosis level of the two cell lines was significantly affected by silencing of the DNMT3 family. The possible cause is that cell-species specificity may influence the apoptotic process. For example, it has previously been reported that p53 is necessary for DNMT to induce cell apoptosis (28). Secondly, cell apoptosis-associated regulatory genes may be activated by DNMT3 silencing, thereby stimulating apoptosis in $\mathrm{HCC}$ cells. Provided that $D N M T 3 b$ silencing may promote the expression of proapoptotic genes and negatively acting cell cycle regulators, this may be an explanation for the host cells proliferating so poorly (26).

Additionally, the deficiency of DNMT3b in HCC cells affected the invasive potential of the cells and also significantly compromised the ability of the cells to migrate, which indicates that the expression of the genes that promote cell migration is influenced by DNMT3b-mediated DNA methylation. This phenomenon is not restricted to HCC cells, but has also been observed in cells obtained from human colorectal, breast and lung cancers (29-31). These results indicate that inhibition of DNMT3b expression decreases the migration and invasion of HCC cells.

The present study also used the previously identified DNMT3b-regulated genes derived from HCC (32) and other types of cancer (33), to examine the associations between DNMT and the genes methylated in HCC cells. The most notable aspect of the present findings was that selective loss of DNMT3b led to complete or partial demethylation of the MTSS1, RASSF1a and APC gene promoters. In addition, despite the methylation status of the CCND1, RB1 and CASP8 gene promoters not being determined, the finding that apoptosis and proliferation decreased in response to DNMT3b loss indicates that these gene promoters may also be targeted by DNMTb. 
A
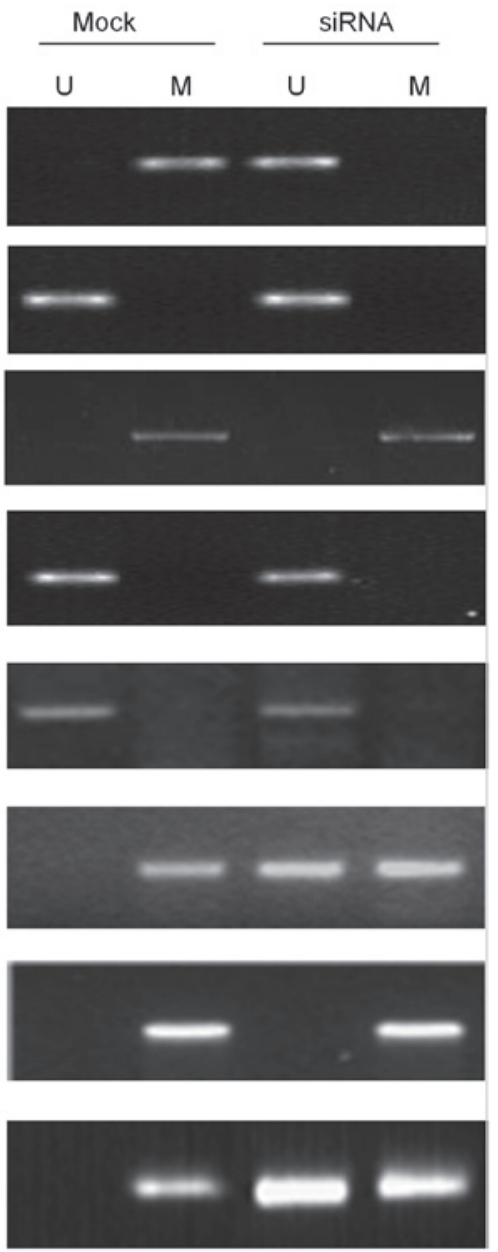

SMMC-7721
B

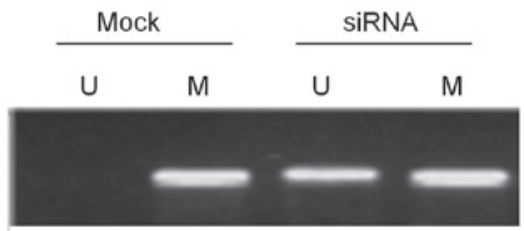

CCND1

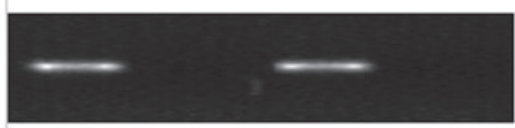

FHIT

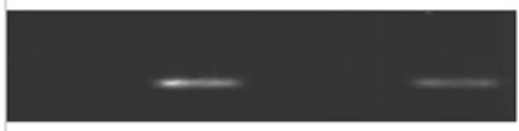

RB1

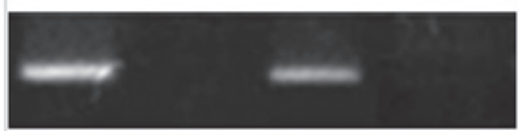

CASP8

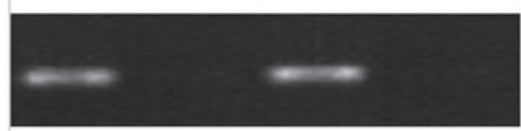

MTSS1

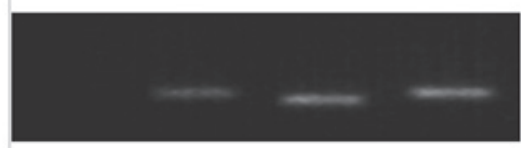

P16

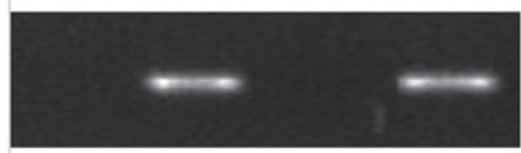

APC

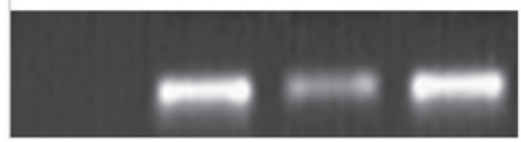

BEL-7402

Figure 4. Presence of PCR product indicated by methylated (lane M) or unmethylated (lane U) alleles. MSP analysis of the RASSF1a, APC, MTSS1,CCND1, RB1, P16, CASP8 and FHIT genes in mock control and siDNMT3b-transfected cells. Results of MSP performed in (A) SMMC-7721 and (B) BEL-7402 cells. $\mathrm{U}$, amplified using unmethylated primer; M, amplified using methylated primer; siRNA, small interfering RNA; MSP, methylation-specific polymerase chain reaction. siRNA, small interfering RNA.

As reported by previous studies (31), it is important to note that although DNMT3b levels were reduced by $75 \%$, the remaining $25 \%$ of methylase activity was insufficient to maintain the methylation status of several of the gene promoters.

A previous study found that the MTSS1 promoter region was sparsely methylated, and the methylation inhibitors failed to abolish DNMT3b-mediated silencing of MTSS1 (34). The DNMT3b protein was found to bind directly to the 5'-flanking region of the MTSS1 gene to inhibit transcription (35). The functional role of MTSS1 was also investigated using in vitro and in vivo tumorigenicity assays (36). As a result, it was identified that MTSS1 exerted tumor suppressor effects and arrested cells in the $G_{2} / M$ phase, but not the $G_{1} / S$ phase, of the cell cycle when the expression of MTSSI was depleted or overexpressed in HCC cells (35). Another previous study also provided experimental evidence that revealed the direct involvement of $\delta D N M T 3 B 4$ in regulating $R A S S F 1 a$ promoter methylation in human lung cancer cells. Knockdown of $\delta D N M T 3 B 4$ expression by siRNA resulted in a rapid demethylation of the RASSFla promoter and recovery in the expression of RASSF1a mRNA. However, the knock-down of $\delta D N M T 3 B 4$ demonstrated no effect on the pl6 promoter in lung cancer cells (37). In addition, genetic alterations in the FHIT gene, such as DNA hypermethylation, have been detected in liver cancer cells at a high frequency, with abnormal transcripts and reduced expression at the RNA and protein levels being observed. Therefore, the loss of FHIT expression may be strongly associated with the pathogenesis and establishment of human malignancies (38-40). Data from a previous study revealed that DNMT3b siRNA induced an increase in the expression of FHIT, but DNA methylation of the FHIT gene was not influenced by the DNMT3b siRNA (41). The present data further confirmed this phenomenon. The present results indicated that DNMT3b-mediated regulation of the expression of certain genes may not occur through methylation of the promoter region. Therefore, DNMT3b regulated gene expression, but DNMT3b did not act as a methylase in the present study.

Overall, the present data demonstrate that silencing DNMT3b expression causes hypomethylation of specific sets of gene promoters and increases the expression of distinct sets of genes in HCC cell lines. The results reported in the present study increase the understanding of the mechanisms of DNA methylation regulation in HCC cells. Future development of the study may be useful for assessing the specificity of 
emerging action based on the altered expression of associated regulative genes, particularly for methylation-silenced genes.

\section{Acknowledgements}

This study was supported by the National Natural Science Foundation of China (grant no. 30571814).

\section{References}

1. Wang Z, Cao Y, Jiang C, Yang G, Wu J and Ding Y: Lack of association of two common polymorphisms rs2910164 and rs11614913 with susceptibility to hepatocellular carcinoma: A meta-analysis. PLoS One 7: e40039, 2012.

2. Thomas MB, Jaffe D, Choti MM, Belghiti J, Curley S, Fong Y, Gores G, Kerlan R, Merle P, O’Neil B, et al: Hepatocellular carcinoma: Consensus recommendations of the National Cancer Institute Clinical Trials Planning Meeting. J Clin Oncol 28: 3994-4005, 2010.

3. Lao Y, Wu H, Zhao C, Wu Q, Qiao F and Fan H: Promoter polymorphisms of DNA methyltransferase $3 \mathrm{~B}$ and risk of hepatocellular carcinoma. Biomed Rep 1: 771-775, 2013.

4. Miyake T, Endo K, Honjo S, Hirooka Y and Ikeguchi M: Expression of DNA methyltransferase (DNMT) 1, 3a and 3b proteins in human hepatocellular carcinoma. Yonago Acta Med 53: 1-7, 2010.

5. Lee S, Lee HJ, Kim JH, Lee HS, Jang JJ and Kang GH: Aberrant $\mathrm{CpG}$ island hypermethylation along multistep hepatocarcinogenesis. Am J Pathol 163: 1371-1378, 2003.

6. Roncalli M, Bianchi P, Bruni B, Laghi L, Destro A, Di Gioia S, Gennari L, Tommasini M, Malesci A and Coggi G: Methylation framework of cell cycle gene inhibitors in cirrhosis and associated hepatocellular carcinoma. Hepatology 36: 427-432, 2002.

7. Yang B, Guo M, Herman JG and Clark DP: Aberrant promoter methylation profiles of tumor suppressor genes in hepatocellular carcinoma. Am J Pathol 163: 1101-1107, 2003.

8. Robertson KD and Wolffe AP: DNA methylation in health and disease. Nat Rev Genet 1: 11-19, 2000.

9. Jones PA and Baylin SB: The fundamental role of epigenetic events in cancer. Nat Rev Genet 3: 415-428, 2002.

10. Jones PA: Functions of DNA methylation: Islands, start sites, gene bodies and beyond. Nat Rev Genet 13: 484-492, 2012

11. Hsieh CL: The de novo methylation activity of Dnmt3a is distinctly different than that of Dnmt1. BMC Biochem 6: 6, 2005

12. Bestor TH: The DNA methyltransferases of mammals. Hum Mol Genet 9: 2395-2402, 2000.

13. Oh BK, Kim H, Park HJ, Shim YH, Choi J, Park C and Park YN: DNA methyltransferase expression and DNA methylation in human hepatocellular carcinoma and their clinicopathological correlation. Int J Mol Med 20: 65-73, 2007.

14. Baylin S and Bestor TH: Altered methylation patterns in cancer cell genomes: Cause or consequence? Cancer Cell 1: 299-305, 2002

15. Robertson KD: DNA methylation and human disease. Nat Rev Genet 6: 597-610, 2005.

16. Shen J, Wang S, Zhang YJ, Kappil M, Wu HC, Kibriya MG, Wang Q, Jasmine F, Ahsan H, Lee PH, et al: Genome-wide DNA methylation profiles in hepatocellular carcinoma. Hepatology 55: 1799-1808, 2012

17. Lambert MP, Paliwal A, Vaissière T, Chemin I, Zoulim F, Tommasino M, Hainaut P, Sylla B, Scoazec JY, Tost J, et al Aberrant DNA methylation distinguishes hepatocellular carcinoma associated with HBV and HCV infection and alcohol intake. J Hepatol 54: 705-715, 2011.

18. Um TH, Kim H, Oh BK, Kim MS, Kim KS, Jung G and Park YN: Aberrant $\mathrm{CpG}$ island hypermethylation in dysplastic nodules and early HCC of hepatitis B virus-related human multistep hepatocarcinogenesis. J Hepatol 54: 939-947, 2011.

19. Hu L, Chen G, Yu H and Qiu X: Clinicopathological significance of RASSF1A reduced expression and hypermethylation in hepatocellular carcinoma. Hepatol Int 4: 423-432, 2010.

20. Kondo Y, Shen L, Suzuki S, Kurokawa T, Masuko K, Tanaka Y, Kato H, Mizuno Y, Yokoe M, Sugauchi F, et al: Alterations of DNA methylation and histone modifications contribute to gene silencing in hepatocellular carcinomas. Hepatol Res 37: 974-983, 2007.
21. Yeo W, Wong N, Wong WL, Lai PB, Zhong S and Johnson PJ: High frequency of promoter hypermethylation of RASSF1A in tumor and plasma of patients with hepatocellular carcinoma. Liver Int 25: 266-272, 2005.

22. Csepregi A, Röcken C, Hoffmann J, Gu P, Saliger S, Müller O, Schneider-Stock R, Kutzner N, Roessner A, Malfertheiner P, et al: APC promoter methylation and protein expression in hepatocellular carcinoma. J Cancer Res Clin Oncol 134: 579-589, 2008.

23. Zopf S, Ocker M, Neureiter D, Alinger B, Gahr S, Neurath MF and Di Fazio P: Inhibition of DNA methyltransferase activity and expression by treatment with the pan-deacetylase inhibitor panobinostat in hepatocellular carcinoma cell lines. BMC Cancer 12: 386, 2012.

24. Steine EJ, Ehrich M, Bell GW, Raj A, Reddy S, van Oudenaarden A, et al: Genes methylated by DNA methyltransferase $3 \mathrm{~b}$ are similar in mouse intestine and human colon cancer. J Clin Invest 121: 1748-1752, 2011.

25. Rhee I, Bachman KE, Park BH, Jair KW, Yen RW, Schuebel KE, et al: DNMT1 and DNMT3b cooperate to silence genes in human cancer cells. Nature 416: 552-556, 2002.

26. Jin B and Robertson KD: DNA methyltransferases, DNA damage repair, and cancer. Adv Exp Med Biol 754: 3-29, 2013.

27. Xu J, Fan H, Zhao ZJ, Zhang JQ and Xie W: Identification of potential genes regulated by DNA methyltransferase $3 \mathrm{~B}$ in a hepatocellular carcinoma cell line by RNA interference and microarray analysis. Yi Chuan Xue Bao 32: 1115-1127, 2005.

28. Du YF, Liang L, Shi Y, Long QZ, Zeng J, Wang XY and He DL: Multi-target siRNA based on DNMT3A/B homologous conserved region influences cell cycle and apoptosis of human prostate cancer cell line TSU-PR1. Genet Mol Biol 35: 164-171, 2012.

29. Kassis ES, Zhao M, Hong JA, Chen GA, Nguyen DM and Schrump DS: Depletion of DNA methyltransferase 1 and/or DNA methyltransferase $3 \mathrm{~b}$ mediates growth arrest and apoptosis in lung and esophageal cancer and malignant pleural mesothelioma cells. J Thorac Cardiovasc Surg 131: 298-306, 2006.

30. Beaulieu N, Morin S, Chute IC, Robert MF, Nguyen H and MacLeod AR: An essential role for DNA methyltransferase DNMT3B in cancer cell survival. J Biol Chem 277: 28176-28181, 2002.

31. Yaqinuddin A, Qureshi SA, Qazi R and Abbas F: Down-regulation of DNMT3b in PC3 cells effects locus-specific DNA methylation, and represses cellular growth and migration. Cancer Cell Int 8: 13, 2008.

32. Lin CH, Hsieh SY, Sheen IS, Lee WC, Chen TC, Shyu WC and Liaw YF: Genome-wide hypomethylation in hepatocellular carcinogenesis. Cancer Res 61: 4238-4243, 2001.

33. Teneng I, Tellez CS, Picchi MA, et al: Global identification of genes targeted by DNMT3b for epigenetic silencing in lung cancer. Oncogene 34: 621-630, 2015.

34. Xie F, Ye L, Ta M, Zhang L and Jiang WG: MTSS1: a multifunctional protein and its role in cancer invasion and metastasis. Front Biosci (Schol Ed) 3: 621-631, 2011.

35. Fan H, Chen L, Zhang F, Quan Y, Su X, Qiu X, Zhao Z, Kong KL, Dong S, Song Y, et al: MTSS1, a novel target of DNA methyltransferase $3 \mathrm{~B}$, functions as a tumor suppressor in hepatocellular carcinoma. Oncogene 31: 2298-2308, 2012.

36. Wang J, Li J, Shen J, Wang C, Yang L and Zhang X: MicroRNA-182 downregulates metastasis suppressor 1 and contributes to metastasis of hepatocellular carcinoma. BMC Cancer 12: 227, 2012.

37. Wang J, Bhutani M, Pathak AK, Lang W, Ren H, Jelinek J, He R, Shen L, Issa JP and Mao L: Delta DNMT3B variants regulate DNA methylation in a promoter-specific manner. Cancer Res 67: 10647-10652, 2007.

38. Linhart HG, Lin H, Yamada Y, Moran E, Steine EJ, Gokhale S, Lo G, Cantu E, Ehrich M, He T, et al: Dnmt3b promotes tumorigenesis in vivo by gene-specific de novo methylation and transcriptional silencing. Genes Dev 21: 3110-3122, 2007.

39. Sarli L, Bottarelli L, Azzoni C, Campanini N, Di Cola G, Bader G, Iusco D, Salvemini C, Caruso G, Donadei E, et al: Abnormal Fhit protein expression and high frequency of microsatellite instability in sporadic colorectal cancer. Eur J Cancer 40: 1581-1588, 2004.

40. Nelson WG, De Marzo AM and DeWeese TL: The molecular pathogenesis of prostate cancer: Implications for prostate cancer prevention. Urology 57 (Suppl 1): 39-45, 2001.

41. Wang JX, Zhang YG and Zhao LS: Influence of DNA methyltransferase $3 \mathrm{~b}$ on FHIT expression and DNA methylation of the FHIT promoter region in hepatoma SMMC-7721 cells. Hepatobiliary Pancreat Dis Int 8: 273-277, 2009. 